\title{
Some Personal Ruminations on Changing Growth Rates*
}

\section{Des méditations personnelles sur les taux changeants de croissance}

\author{
J. STEFAN DUPRÉ**
}

Nothing I am about to say reflects official views, including any I might come to espouse in my present capacity. Everything I am about to say reflects considerable personal confusion, a confusion that has if anything been augmented by twenty-eight consecutive months of official involvement in pondering the question of changing growth rates and their implications for university systems.

My disciplinary background in political science and economics yielded a measure of preparation for pondering this question. The time-tested axiom of political forecasting is that "the future assuredly lies ahead." As for economic forecasting, the golden rule of that highly developed art is "state a figure or state a year, but never both." I lack formal background in a third kind of forecasting that is also useful - educational forecasting. Experience is beginning to teach me that in this domain the motto is something like the following: "pendula that swing in one direction sooner or later swing in the other," or "plus ça change, plus c'est la même chose."

Experience is also teaching me something else. If you are stuck in a warehouse stocked with explosives, "it is wiser to curse the darkness than light a candle." University systems that confront changing growth rates are indeed stocked with explosive material. I accept as revealed truth all the sad stories that my university friends have told me in this regard.

Over the years, my career has endowed me with government friends as well as university friends. Their stories are just as sad. The days of large automatic revenue increases are long gone and their departure coincides with, first, a need to combat inflation by curtailing the rate of increase in public expenditures, and, second, increasingly vigorous claims on behalf of competing spending programs by ever more intense clientele groups. In this setting, governments may be reluctant to spell out their objectives lest they promise more than they can deliver. For university administrations to enunciate overly detailed internal objectives can be self-defeating if the end result is to sap faculty and staff morale. The same can hold with respect to government objectives if the end result is a public credibility gap.

* Presented to Annual Meeting, AUCC, November 3, 1976

** Professor, Department of Political Economy, University of Toronto. When this paper was presented, Professor Dupré was Chairman of the Ontario Council on University Affairs. 
Our dark warehouse stocked with explosives accordingly provides an environment enormously conducive to enriching our vocabulary of four-letter words. This may be what the present paper produces. Lest the candle-lighting alternative becomes too tempting, we can draw comfort from the fact that none of our forecasting arts amounts to anything that remotely resembles a candle. I am thus fully prepared to join in a vocabulary-building exercise. Before doing so, it happens that I have five matches that I propose to strike ever so cautiously and blow out ever so expeditiously. They may or may not help us to discern a few of the shadows among which we grope when the subject at hand is changing growth rates. I have given my five matches the following names:

1) the Born and the Unborn

2) the Employed and the Unemployed

3) the Qualified and the Unqualified

4) the Certified and the Uncertified

5) the Metropolitan and the Non-metropolitan

\section{The Born and the Unborn}

Birth and non-birth are equally valid facts of life (or non-life). The large numbers born twelve or more years ago represent the final stage of a demographic bulge that will have passed the normal age bracket of full-time university attendance by the mid-nineteen eighties. Those born twelve or more years ago then give way to those not born more recently. The demographic shadows thus yield a near-term prospect of further growth in full-time students to be followed by a longer-term prospect of decline.

The trick question, of course, is what will happen to participation rates. I have some matches to strike on that subject later. For the moment, the prospect of demographic growth followed by decline prompts the following ruminations:

a) With respect to full-time undergraduates, universities will occupy a sellers' market at constant or even moderately declining participation rates for about six more years. Their long-run interests as institutions are probably well served to the extent that they fill whatever empty places remain and then turn away surplus applicants. Additional investment in human and physical capital will consequently be held to a minimum, and universities will face the prospect of long-run decline in their traditional student clientele with a lighter burden of fixed commitments than would otherwise be the case. Furthermore, in that universities by their own restrictive action will have depressed the participation rate as the age bulge peaks, they can perhaps look to a restoration of participation rates to earlier levels as a means of offsetting the advent of demographic decline. Whatever eventually happens to full-time participation rates, the lighter burden of fixed commitments will leave universities in a more flexible position from which to meet the rather different educational demands that may be expected from an ageing population in the longer run.

b) Please note that the above rumination sketches a scenario deemed as probably redounding to the long-run interests of universities as institutions. Their near-term interests may be something else again. In the rough-and-tumble of the estimates process, all public programs lay claim to increases that will be sufficient to maintain real levels of service. The outcome can be disappointing. Witness, in your very own bailiwick, the fate 
of research support at the hands of the federal estimates process in recent years. With respect to provincial operating grans, there is evidence, in a number of jurisdictions at least, that the accommodation of rising student demand has constituted a key point in clinching whatever expenditure priority has in fact been accorded to university systems. At that, the end result has on occasion left something to be desired where inflation is concerned, with the implication that the requisite growth will be accommodated to beat inflation. In the near term, there may accordingly be some validity in the view that universities are damned if they grow and damned if they don't. Whatever the case, severely restricted growth appears to remain in their longer-run interests. In the meantime they might consider praying - especially for reduced inflation and general economic recovery. c) By way of further rumination let me offer a complement if not an alternative to prayer. This may lie in recognizing that the demographic prospects of full-time student growth and decline offer an instance where the university interest and the public interest may not coincide. What appears to serve the long-run university interest is restricted growth while the sellers' market lasts. There is a price to be paid in terms of the public interest if the educational aspirations of those who comprise the tail-end of the age bulge are accordingly frustrated. This price is in large part intensely human, and hence all the more real. The bill is presented to governments at the point where constituents begin to complain about the inaccessibility of campus places. To the extent that considerations of the public interest may lead governments to insist on growth, it will be increasingly imperative to recognize that this is not in the longer term university interest. This being so, governments that choose to pursue the public interest by pushing growth in the near term should be asked to accept a clear-cut responsibility for the university interest in the longer term.

The above ruminations are occasioned by demographic considerations affecting the full-time student clientele. Participation rates are a vast unknown, and I now proceed, with trembling hands, to scratch a few matches in their direction.

\section{The Employed and the Unemployed}

Employment opportunities have an impact on patterns of growth in the university sector, at least according to the conventional wisdom. That wisdom in turn draws a degree of sustenance from my limited observations of shifts in program choice. Or at least I should say that my own economic bias leads me to associate shrinking graduate enrolment in the physical sciences with student perceptions of currently dim employment prospects in these disciplines. By the same token, I link the apparent popularity of M.B.A. programs to student perceptions of more buoyant employment prospects in private enterprise. Right or wrong, these observations are too microscopic for my present purposes.

In striking a match labelled "the employed and the unemployed." I discern two items in the shadows. The first involves swings in the business cycle, the second relates to the longer-run structure of the economy.

In economic parlance, high rates of unemployment tend to have a positive effect on participation rates because they reduce the foregone earnings costs of university attendance. In everyday terms, the immediate lack of job prospects induces individuals to look upon university attendance as a pallatable alternative to unemployment insurance or welfare assistance. I am currently observing in my own jurisdiction a situation where recent 
enrolment growth has run ahead of demographic trends. The full-time participation rate has been increasing, and though I acknowledge that this may be due to a host of factors, my economic intuition leads me to feel that current levels of unemployment provide a partial explanation.

Cyclical employment patterns are one thing; employment opportunities that are determined by long-term shifts in the structure of the economy are another. For the last thirty years, the most remarkable structural change in our economy has been the relative growth of the public sector, health and education included. We can hardly expect this relative growth to continue over the next thirty years for any of a number of reasons with which I will not detain you. We cannot expect, either, a continuation of the rapid relative decline of the agricultural sector that accompanied the growth of the public sector during the last several decades.

The outlook for the balance of this century, in brief, is for much greater stability in the sectoral distribution of employment opportunities. Please note carefully, at this juncture, that the enormous growth in demand for highly educated employees we have experienced since the War coincided with the major sectoral shifts of the last thirty years. Indeed, one authority estimates that up to 70 per cent of the relative increase in positions involving a high degree of education was due to changes in the sectoral composition of the economy, with the remainder due to increases in educational attainment within sectors. ${ }^{1}$

I hasten to extinguish my employment-unemployment match. What I have discerned in its flickering light are forces that may accentuate the demographically fed prospects of near-term enrolment growth followed by longer term decline. To the extent that recovery from the current economic downswing is slow in materializing, the near-term effect of unemployment could be upward pressure on participation rates and hence on the already age-swollen demand for full-time university attendance. In the longer run, relative stability among economic sectors, consequent softening in demand for highly educated labour, and the increasingly clear perception by potential students of reduced returns from education may accelerate the fall in full-time student numbers that demography has in store from the mid-eighties to the mid-nineties.

Restricted growth during the present sellers' market may therefore be all the more in the long-run university interest to the extent that future declines in full-time numbers may be precipitous. On the other hand, continued cyclical unemployment may accentuate the stake of the public interest in rapid near-term growth.

\section{The Qualified and the Unqualified}

I too read MacLean's Magazine. The last wave of educational reform apparently brought in its wake a marked deterioration in standards of numeracy and literacy. Many university spokesmen confirm that their students are now less qualified than they used to be. I am given to understand that some even worry about the extent to which university standards emulated those in our schools.

From the Globe and Mail, I most recently learn that the golden axiom of educational

${ }^{1}$ Stephen P. Dresch, "Human Capital and Economic Growth," Paper Prepared for the U.S. Congress Joint Economic Committee (New Haven: Institute for Demographic and Economic Studies, 1976). 
forecasting is as reliable as ever. The pendulum is now shifting in the other direction. Compulsory subjects are on the way in; permissiveness is on the way out. Tests and examinations are being rediscovered.

In the dark warehouse of changing growth rates, a return to "standards" may offer the following twin prospects. One is that the near-term pressure for university admission can be reduced by more stringent definitions of what constitutes a "qualified" applicant. A second is that the advent of higher standards may spell trouble by accentuating enrolment decline in the longer run. In the flickering light of my Qualified-Unqualified match, I have trouble discerning likelihood in either prospect. There is an appreciable lag between the introduction of educational "reform" and its effect on student "qualifications." This lag may well embrace the entire period in which universities occupy a sellers' market. To invoke during that time allegedly sub-standard qualifications as a reason for restricting student entry will be to suggest that the applicants of the next few years may pay for the "sins" of the school systems that produced them. I strongly doubt that this can be perceived as being in line with the public interest; here, in other words, is a container filled with particularly dangerous explosives.

As to the longer-run possibility that more stringent standards could deflate university participation rates, what I discern by my meager light is that this hypothesis is weak with respect to students generally and erroneous with respect to part-time students in particular. I am admittedly the rankest of amateurs with respect to educational forecasting, but I am impressed by the proposition that students have an enormous capacity to measure up to expectations. Higher standards are far more likely to yield higher levels of performance than higher failure rates. Any positive effect on failure rates may well be mitigated by a reduction in drop-out rates.

With respect to part-time students, I discern the genuine possibility that higher standards may actually have a positive effect on growth rates. Perceptions to the effect that standards have become "more rigorous" and that an earlier educational experience was perhaps "deficient" may encourage individuals to undertake part-time study and their employers to induce them to do so.

\section{The Certified and the Uncertified}

Having been exposed to a good deal of talk about the undue emphasis that our society attaches to formal "credentials," I began to wonder if the emergence of an "uncertified society" might produce spectacularly negative growth rates for universities and educational institutions generally. In the light of my Certified-Uncertified match, what I see makes the prospect of an uncertified society totally unlikely. Let me offer the following points:

a) Formal academic credentials are rightly downgraded when employers no longer view them as a guide to employee qualifications. The extent to which, in the last several years, our educational systems turned out illiterate high school graduates and semi-literate university graduates produced a valid reason for advocating a flight from credentials. As the educational pendulum swings back, however, credentials will regain credibility as an employment screening device.

b) A tighter labour market increases competition for advancement among employed 
individuals. Part-time study, say toward a Bachelor of Commerce, a Master of Engineering or a Master of Business Administration accordingly becomes increasingly attractive as a means whereby the employee can "signal" to his or her employer that he or she is really up-and-coming. Here the trends are toward more not less demand for certification.

c) A reduction in the growth of employment opportunities in the public sector will if anything increase the tendency of employing officials to favor a high degree of certification. I personally think that this is a tendency that should be held in check. That tendency, however, is there, and again it is toward more certification, not less. d) In the shadows of the public sector, there may lurk an even stronger tendency in the direction of more rather than less certification. I discern the following as I ruminate about the future coexistence of a relatively stable public employment sector with public service unions in a collective bargaining framework. In a softer labour market where unions find growing resistance to large across-the-board wage demands, the bargaining process can be conducive to monetary rewards for employees who accumulate additional educational credentials. From the union standpoint, this still represents a gain at the bargaining table. From the management perspective, the monetary rewards for additional credentials are only earned by the employees who achieve the requisite level of certification, and are accordingly viewed as less costly than across-the-board salary adjustments. It therefore may well be, to pick but one example, that there is more substance to the prospect of a continued escalation of teacher credentials - from B.Ed. to M.Ed to Ed.D. - than the merely ambitious dreams of faculties of education. Multiplied by many public service occupations, the likelihood of buoyant demand for part-time and continuing education is all the more considerable.

e) I hesitate to say much about continuing education in the professions generally. In that my topic is changing growth rates, I will simply state my agreement with the opinion of those who view this kind of education as likely to occasion increasingly buoyant demand for university services in the long run. The kinds of services demanded, however, are likely to be quite different from those that have been dispensed to the traditional parttime student who annually takes one or two courses while maintaining a full-time job. Demand is likely to favor full-time offerings over periods ranging from several weeks to several months.

\section{The Metropolitan and the Non-metropolitan}

The final match I wish to strike is in the direction of a corner of our dark warehouse that I think has been least explored. I refer to the matter of geographical location vis-à-vis changing growth rates and in particular to the rather different positions that universities may come to occupy according to whether they find themselves in major metropolitan areas or elsewhere.

If geographical location has been a secondary concern in university planning, this is because full-time students are relatively mobile. With regard to the immediate prospect of further growth in full-time student numbers, governments and universities should of course seek out all means of further enhancing student mobility so that growth is accommodated by surplus places wherever they may exist in Canada. In that this paper is delivered to a national audience, I must in this respect seize the opportunity to record 
my strongest personal views to the effect that interprovincial as well as intra-provincial student mobility is now more important than ever before. During the coming few years of full-time student growth, it is in the interest of all universities and governments to ensure that demand is accommodated wherever excess capacity exists. Birth rates, migration rates and economic structure of course differ from one province to the other. Some provincial university systems will be under greater pressure than others. It may be tempting for certain systems under particularly great pressure to consider fee differentials for out-of-province students, thereby inducing a domino effect. Nothing could be more damaging. We must advance the cause of student mobility and reject all potential barriers to such mobility.

Having made this plea, I return to the greater importance that I believe should be attached to geographical location in university planning for the long run.

Some of the earlier ruminations in this paper are to the effect that demand for parttime and continuing education will be buoyant for the balance of this century. The problem with part-time students who follow the conventional route of combining course work with full-time jobs is that they are tied to the locality in which they are employed. I ask you now to consider the unconstrained urban future that might find most Canadians in Montreal, Toronto and Vancouver by the year 2000. Granting that this is an extreme scenario and that a combination of socioeconomic factors and government policies may save us from this fate, I will add Halifax and Quebec, Ottawa and Hamilton, and Winnipeg, Edmonton and Calgary to the list of metropolitan areas in which our population growth might be particularly concentrated. You may wish to add a few more to the list but please - no idle exercises in civic boosterism!

The prospect of growth in conventional part-time students is very real for the institutions located in the metropolitan areas on the list. Indeed, part-time growth will be accentuated by the very process of population concentration. But I see no such growth, and indeed the prospect of decline for all institutions that are excluded from the list. The exclusions do not simply amount to the majority of Canadian universities; they embrace entire provincial systems.

We have here a planning puzzle that intrigues me enormously. It has national as well as provincial dimensions. In the light of our urban future, two long-range considerations beckon. First, if our future is one of geographically concentrated growth in part-time students who lack mobility coupled with a decline in mobile full-time students, institutions in major metropolitan areas may wish to consider vacating a portion of the declining full-time student market in favor of universities located elsewhere. Second, planning for the expanding new forms of continuing education might consider assigning the lead role to non-metropolitan universities. The kind of continuing education that involves concentrated periods of full-time university attendance not only permits student mobility; it is perhaps at its best when the students are geographically removed from the site of their professional occupations.

By way of concluding all these ruminations on changing growth rates, let me return to my introduction. With respect to educational forecasting, I have kept my eye on the pendulum. In the matter of economic forecasting, I have stated no numbers and indeed stated decades instead of years. As for political forecasting, may I assure you that the future does indeed lie ahead. Here we are in our dark warehouse. I struck five matches. The were all I had. 